Geopolítica(s) Revista de estudios sobre espacio y poder ISSN: 2172-3958

https://dx.doi.org/10.5209/geop.69351

\title{
Los mapas y calendarios de la pandemia
}

\author{
Carlo Emilio Piazzini Suarez
}

Recibido: 8 de mayo de 2020 / Aceptado: 10 de mayo de 2020

Resumen. La pandemia de COVID-19 asociada al virus SARS-CoV-2 ha estado generando una serie de efectos severos sobre las experiencias de espacio y tiempo social, que amerita comenzar a identificar y comprender. En este texto se propone una aproximación inicial a la problemática, examinando cómo esas experiencias podrían estar dando continuidad o transformando regímenes espaciotemporales que ya venían en marcha. Para el efecto se analizan las medidas de confinamiento y regulación de los ritmos de la vida cotidiana, así como las proyecciones del comportamiento de la pandemia en mapas y calendarios. Ello conduce a identificar cómo operan unas geopolíticas y cronopolíticas de la pandemia, y a proponer algunas estrategias de cara a lo que sigue.

Palabras clave: pandemia de COVID-19; espacio-tiempo; geopolítica; cronopolítica; cartografía

\section{[en] Maps and Calendars of the Pandemic}

\begin{abstract}
The COVID-19 pandemic associated with the SARS-CoV-2 virus has been generating a series of severe effects on the experiences of social space and time, which deserves attention and understanding. In this text, an initial approach to the problem is proposed, examining how these experiences could be giving continuity or transforming space-time regimes that were already under way. For this purpose, measures of confinement and regulation of the rhythms of daily life are analyzed, as well as projections of the behavior of the pandemic on maps and calendars. This leads to identify how geopolitics and chronopolitics of the pandemic operate, and to propose some strategies for what follows.
\end{abstract}

Keywords: COVID-19 pandemic; space-time; geopolitics; chronopolitics; cartography.

\section{[pt] Os mapas e calendários da pandemia}

Resumo. A pandemia de COVID-19 tem gerado uma série de efeitos drásticos nas experiências do espaço e do tempo social, que merecem ser identificados e compreendidos. Neste texto, é proposta uma abordagem inicial ao problema, examinando como essas experiências podem dar continuidade ou transformar regimes de espaço-tempo que já estavam em andamento. Para tanto, são analisadas medidas de confinamento e regulação dos ritmos da vida cotidiana, bem como projeções do comportamento da pandemia em mapas e calendários. Isso leva a identificar como a geopolítica e a cronopolítica da pandemia operam e a propor algumas estratégias para o futuro próximo.

1 Profesor Titular, Instituto de Estudios Regionales, Universidad de Antioquia, Colombia.

E-mail: carlo.piazzini@udea.edu.co 
Palavras-chave: pandemia da COVID-19; espaço-tempo; geopolítica; cronopolítica; cartografia.

Sumario. Introducción. 1. Quedarse en casa. 2. Estar en cuarentena. 3. Los mapas del tiempo. Reflexiones finales. Referencias.

Cómo citar: Piazzini Suárez, C. E. (2020). Los mapas y calendarios de la pandemia. Geopolítica(s). Revista de estudios sobre espacio y poder, 11(Especial), 265-274.

"Mi mayor inquietud es que no aprendamos nada de la crisis, cuando esta nos está demostrando como si fuera un medio de contraste inyectado en un cuerpo cuáles son los males que afectan a nuestra sociedad”.

Carolin Emcke

\section{Introducción}

Por estos días, desde los más diversos lugares y condiciones sociales, se hacen las mismas preguntas: ¿a partir de cuándo podrá hablarse de un después de la pandemia?, ¿cómo será el mundo en post-pandemia?, ¿será posible retornar a la normalidad, o se tratará de una nueva normalidad, e incluso de algo radicalmente diferente? Buscando respuestas, algunos reelaboran sus visiones del pasado, para valorarlo con nostalgia, incluso como algo a lo que habría que retornar. Otros, ven en las crisis un signo de la imperiosa necesidad de realizar cambios, proponiendo ir hacia viejas o nuevas utopías. Otros más, sin prever muchas transformaciones e incluso sin confianza en el futuro, se han ido acomodando a las nuevas situaciones, aprovechando la oportunidad para permanecer, y aún afirmarse en sus intenciones previas. En todos los casos, se trata de ecuaciones que operan en las relaciones entre presente, pasado y futuro, y, en ese sentido, es evidente que tienen que ver con el asunto del tiempo. Menos evidente, es que también involucran una dimensión espacial.

Pero la nitidez con la cual puede hacerse visible la importancia que ambas dimensiones han adquirido durante esta crisis, puede constatarse en dos de los imperativos más comunes que la acompañan: quedarse en casa y estar en cuarentena, con lo cual, millones de personas hemos estado sujetas a un confinamiento espaciotemporal. En este sentido, resulta pertinente, como planteo en este breve texto, aprovechar la crisis de la pandemia de COVID-19, como medio de contraste para ensayar un diagnóstico acerca de posibles cambios o continuidades que se están produciendo en las experiencias espaciotemporales de los sujetos y sociedades contemporáneas. Me refiero en general a percepciones, concepciones y prácticas sociales que emergen, pero que también transforman particulares regímenes de ordenamiento del espacio y el tiempo ${ }^{2}$.

Además de ser este un ejercicio sobre la marcha, es necesario precisar que la pandemia, nuestro "medio de contraste", también está incidiendo en la configura-

2 Hago aquí uso ampliado del concepto de regímenes de historicidad de Hartog (2007, p.30), como herramienta que permite describir, analizar y comprender la manera en que, en cada presente histórico, se tejen las relaciones entre pasado y futuro, llegando a configurar ciertos ordenamientos temporales. En cuanto a la dimensión espacial, se trata de los órdenes que rigen particulares imaginaciones geográficas. 
ción de las experiencias espaciotemporales, y por supuesto, en la manera en que nos proponemos comprenderlas. Tal vez sea pertinente aclarar también, que sin pretender ocultar la agencia que el virus bautizado como SARS-CoV-2, causante de la enfermedad que se ha acordado denominar COVID-19, ha tenido en todo esto, vivimos la pandemia como resultado de un ensamblaje más amplio, que además del virus, está hecho de las prácticas científicas y clínicas, y dispositivos tecnológicos que buscan conocer y controlar sus comportamientos, de las medidas que los gobiernos adoptan de buen o mal grado para controlar las infecciones, así como del despliegue mediático de estas prácticas y dispositivos, y sus consecuencias sociales.

\section{Quedarse en casa}

Una de las formas más crudas en que la pandemia está afectando nuestras experiencias espaciales, es el confinamiento. Como es de sobra conocido, quedarse en casa hace parte de una amplia serie de mandatos o recomendaciones de distanciamiento, mediante los cuales se busca eliminar, no sólo el contacto entre los cuerpos de las personas, sino inclusive entre partes del mismo cuerpo. La exigencia de usar máscara y guantes no sólo busca evitar el contagio interpersonal, sino también entre nuestras propias manos y vías respiratorias. Con esta medida se quiere establecer una barrera que opera de la misma manera que las fronteras rígidas establecidas en los muros que separan habitaciones y casas, y en los límites entre barrios, municipios, regiones y países. Concretando este funcionamiento sucesivamente escalar, la vigilancia y control de los gestos y movimientos de las personas en la micro geografía de la vida cotidiana, ha implicado la adopción de protocolos semejantes a los que, antes de la pandemia, se aplicaban fundamentalmente a las fronteras internacionales más custodiadas. Hoy se plantea incluso la expedición de salvoconductos o pasaportes de inmunidad, para transitar en lugares y regiones intraestatales.

A la rígida demarcación de fronteras ya existentes $-\mathrm{y}$ al establecimiento de otras nuevas - se aplican, como era de esperar, vigilantes, policías, militares y personal médico. Pero no son pocos los ciudadanos del común que se suman a la tarea, vigilando los movimientos que se producen en sus vecindarios. En no pocos casos, esto ha llevado a generar prácticas de discriminación, exclusión y agresión del sospechoso, del extraño o del extranjero. Asociados a todo este despliegue policivo, están los dispositivos tecnológicos, tales como termómetros, cámaras, drones y aplicaciones para la ubicación de teléfonos móviles, que en su conjunto están generando lo que podemos denominar una hiperterritorialización de los espacios cotidianos.

Podría plantearse que esta replicación y ampliación sistemática de fronteras rígidas, desde lo corporal a lo global, concreta y fortalece uno de los rasgos centrales de la imaginación geopolítica moderna, tal como la ha descrito Agnew (2003); en particular la centralidad de los Estados nacionales como forma hegemónica de especialización del poder, un aspecto que, por cuenta de los procesos recientes de globalización, había dado señales de debilitamiento. Ello se hace particularmente evidente en las cartografías de la pandemia. En el popular mapa en tiempo real de la COVID-19, elaborado por la Johns Hopkins University (2020), el comporta- 
miento espacial del virus se distribuye con estricto apego a los espacios estatales oficialmente reconocidos. De igual manera, las respectivas entidades nacionales encargadas de hacer oficiales las cifras domésticas de la pandemia vierten en mapas oficiales los datos cotidianos, con lo cual reafirman la estructura de su geografía política. Todo ello pese a que ha sido, precisamente trascendiendo las fronteras, que los contagios se han extendido.

De forma simultánea, el orden escalar y jerarquizado de territorios anidados (desde el cuerpo hasta las fronteras internacionales), refuerza un comportamiento espacial que ya venía funcionando desde hace bastante tiempo. En efecto, las jerarquías escalares han contribuido a demarcar y controlar en específicos espacios el alcance de las relaciones sociales, incluidas las relaciones de género, las actividades económicas y la toma de decisiones políticas (Brenner, 2001). Ello se ha hecho particularmente visible, por cierto, en la manera en que no pocos alcaldes, gobernadores y presidentes o primeros ministros, han aprovechado esta pandemia como una "escenografía del poder", para contrarrestar su impopularidad o magnificar sus actuaciones. Basados en el poder que les concede, mediante decretos de excepción, cerrar y abrir puertas y mercados, y marcar los ritmos cotidianos de la gente y las organizaciones, logran, consciente o inconscientemente, tocar o trastocar el orden preexistente de encadenamiento jerarquizado entre diferentes esferas de control espacial. En muchos casos, lo que se ha hecho es contribuir a reafirmar dicho orden, mediante alianzas y manifestaciones de lealtad política. En otros, se ha desafiado ese orden, lo cual parece conceder aún más réditos políticos, o por lo menos mayor visibilidad. Dependiendo del imperativo que se haya decretado desde las jerarquías más altas, llámense organizaciones mundiales o regionales de la salud, o presidencias y ministerios, oponerse a las recomendaciones de confinamiento, o negarse a abrir el mercado, aunque decisiones en principio diferentes, generan el mismo efecto de fricción y ponen en riesgo de desvertebramiento las estructuras escalares tradicionales. Las escalas, por más que nos parezcan un asunto dado, son producciones históricamente contingentes (Brenner, 1998), por lo cual, estas insurrecciones frente a la autoridad de organismos multilaterales o Estados nacionales, podrían estar anunciando algunas transformaciones, y más precisamente, procesos de reescalamiento.

Por otra parte, diferentes aspectos de la pandemia han sido utilizados en tensiones internacionales que ya venían dándose. La guerra comercial declarada por el gobierno de los Estados Unidos a China, ha encontrado otros medios para continuar, en las denuncias sobre ocultamiento de información acerca del origen del virus y en teorías conspiratorias sobre su producción en laboratorio por parte de China. Así mismo, en la preocupación con la cual el gobierno norteamericano ha observado el despliegue de ayudas humanitarias desde China y Rusia a países que han sido históricamente sus aliados. Estos casos son los que, en un lenguaje tradicional, ameritarían hablar de una geopolítica de la pandemia. No obstante, desde una perspectiva más amplia, es claro que las relaciones entre espacio y poder se están dando en todas las escalas y formaciones espaciales aquí identificadas, con lo cual estamos hablando de una geopolítica no circunscrita a lo internacional, que se proyecta incluso al ámbito espacial más íntimo de los cuerpos. 


\section{Estar en cuarentena}

Acuerdos y disputas políticas también se vienen dando en torno de la definición de los tiempos en que deberían regir las medidas de distanciamiento comúnmente conocidas como cuarentena, los plazos de su desmontaje y la fecha de retorno a nuevas o viejas normalidades. Ello lleva al segundo punto de este análisis: aquello que en propiedad es el ámbito de la cronopolitica, en donde se ordenan y administran los ritmos cotidianos de la vida social, los grupos de edad de las personas, pero, además, se incide en la manera en que los sujetos y los grupos sociales valoran desde el presente las experiencias del pasado y definen los caminos a seguir.

De forma simultánea al saturado despliegue de mandatos y recomendaciones con implicaciones espaciales (distanciamiento, contacto, apertura o cierre), la gramática de la pandemia incluye una serie importante de términos cronológicos: paciente cero, índice de contagio, tiempo de duplicación y curva de la infección, entre otros. Con ellos se construyen, día a día, unos calendarios de la pandemia, los cuales son masivamente publicitados por los medios de comunicación. Allí se marcan los eventos sucedidos y por suceder: las horas, días y meses que van desde el inicio real o hipotético de los contagios; las fechas de implementación de las medidas para la contención de las infecciones; la previsión del momento en que éstas se podrían flexibilizar; y las especulaciones sobre la época de posible entrada en funcionamiento de una vacuna o de superación de la enfermedad.

Estos calendarios, además de ser instrumentos políticos, pueden producir entre los ciudadanos un estado permanente de expectativa y zozobra, en la medida en que proyectan señales de mejoría o empeoramiento de la situación que se transforman velozmente conforme cambian las cifras locales y globales de la pandemia. En primera instancia, ello contribuye a incrementar las sensaciones de incertidumbre frente al futuro, que, siguiendo los estudios de Hartog (2007), ya venían haciendo carrera desde la segunda mitad del siglo XX, como parte fundamental de lo que denominó un régimen de historicidad presentista. Dicho régimen, emergió sobre las promesas incumplidas de un futurismo basado en los ideales de progreso y bienestar. Con todo, hay que decir que, mientras los ideales de desarrollo y crecimiento económico siguieron jalonando buena parte de las políticas de los Estados, en no pocos sectores sociales se generaron esperanzas de un futuro alternativo que por lo menos no resultaba tan pesimista.

Para quienes hemos vivido lo suficiente como para haber experimentado el cambio entre siglos, tal vez los efectos del confinamiento generados por la pandemia, no logren borrar por completo la huella que han dejado las experiencias de otros tiempos. Pero para las generaciones más jóvenes, que se encuentran estructurando sus expectativas de futuro, los calendarios de la pandemia pueden resultar mucho más desesperanzadores y en todo caso cruciales para la configuración de sus sentidos del devenir. A ello se suma que la muchedumbre de pantallas, dispositivos táctiles, robots, juguetes sexuales, y ropas de marca, vienen contribuyendo tenazmente a forjar una experiencia fugaz y presentista del tiempo. Por cuenta del consumo desmesurado de estas y otras mercancías, y de la fabricación de modas que son cada vez más pasajeras, el presente se comprime, aún más, entre un futuro demasiado anticipado, y un pasado que llega demasiado pronto, tomando la forma de la obsolescencia y las basuras. 


\section{Los mapas del tiempo}

En estricto sentido, la distinción entre espacio y tiempo es muchas veces sólo de orden analítico. En su conjunto, los mapas y calendarios de la pandemia se articulan para impactar los imaginarios geográficos acerca del devenir. Conforman en esa articulación unas geografías del tiempo (May y Thrift, 2001), en las cuales el pasado y el futuro residen en determinados lugares del planeta.

Hasta el momento en que escribo este texto, los cálculos de comportamiento cronológico y espacial de las estadísticas de contagio, ubican su origen, entre noviembre y diciembre de 2019 en China y países vecinos, desplegándose a inicios de 2020 hacia Oceanía, otros países de Oriente y Europa, para luego proyectarse hacia Norteamérica y, finalmente, llegar a África y Latinoamérica. La imagen resultante es la de un sentido espaciotemporal según el cual las diferentes regiones y países del planeta, han ido subiendo o bajando por la curva de la pandemia, yendo de oriente a occidente y de norte a sur. Los observadores interesados en aprender de este comportamiento, dependiendo de su ubicación respecto de este cronotopo pandémico, miran con atención lo sucedido en Asia o Europa como el futuro al que deberían enfrentarse próximamente. Sin que hayan dejado de hacerse estigmatizaciones, como la de una dudosa zoofagia en China o la de una relajada proxemia y falta de disciplina en Italia, los observadores toman atenta nota de lo sucedido al oriente o al norte, para tratar de predecir el futuro que les espera. Hoy se dice que China y Corea ya han descendido la curva, exaltando su capacidad de aplicar tecnología punta para controlar la pandemia: que la mayoría de los países de Europa, sorprendidos abruptamente por las infecciones, comienzan por fin el declive, no sin riesgos de retroceso; que Estados Unidos acaso está alcanzando la cumbre y pagando un alto precio por no aplicar a tiempo medidas de cuarentena; y que Latinoamérica y África, están apenas subiendo la cuesta, con inmensos riesgos, dada la precariedad de sus capacidades médicas y sanitarias.

Los sinuosos gráficos estadísticos del comportamiento cronológico de la COVID-19, son pues muy parecidos a los altibajos de una historia lineal, escrita esta vez con cifras de infectados, decretos de confinamiento, dispositivos tecnológicos e indicadores económicos. Con ello se genera la percepción de que el futuro está en el oriente de Asia, pasa sucesivamente por Europa, hace estragos en USA y está llegando a África y Latinoamérica, cargado de miedos e incertidumbres. En este sentido, podría decirse que la Pandemia está contribuyendo a una cierta modificación de la manera en que se venían ordenando temporalmente las diferencias espaciales.

Aquí es útil recordar que la temporalización de las alteridades ha sido un recurso muy importante en la estructuración de las imaginaciones geopolíticas y cronopolíticas de la modernidad (Agnew, 2003; Fabian, 1983). Por lo menos desde el siglo XVIII, en virtud de un régimen de historicidad futurista que situaba la punta de lanza de la Historia (con mayúscula) en Europa central, el lugar geográfico del futuro ha ido moviéndose gradualmente hacia el mundo anglosajón y ya en el siglo XX, concretamente hacia Norteamérica. Desde allí se generaron sucesivamente señales de progreso, crecimiento económico y desarrollo tecnológico, que los demás países del mundo deberían alcanzar para salir del atraso y orientarse firmemente en la vía hacia un futuro mejor. De este ordenamiento espaciotemporal emergió la distinción entre países del primer, segundo y tercer mundo, así como 
aquella otra, más reciente, entre países desarrollados, en vías de desarrollo o subdesarrollados.

Ahora bien, en estas narrativas teleológicas y lineales de la Historia, en las últimas décadas el lugar del futuro venía disputándose entre Norteamérica, Europa occidental y algunos países asiáticos. El crecimiento económico experimentado en Japón y Corea del Sur, pero sobre todo en China, los había puesto en el mapa global como nuevas potencias. Lo cual se fortalece ahora, en el mapa del tiempo que emerge con la pandemia. Pero no se contaba con que desde el nuevo lugar del futuro viniera precisamente una pandemia. No se trata aquí, desde luego, de una estigmatización de los países de Oriente como sedes naturales de virus y contagios humanos. Estos pueden mutar y han mutado en muchas otras partes del planeta. Se trata, en primer lugar, de llamar la atención acerca de la estrecha relación que hay entre los principales circuitos de la globalización económica y financiera ${ }^{3}$, y la cadena principal de la transmisión de la COVID-19. En segundo lugar, que dado el lugar que ocupa el oriente de Asia en la geografía mundial del futuro, por lo menos en un escenario de corto plazo, dicho futuro se proyecta como una ambigua mezcla de señales de prosperidad, por la vía del crecimiento económico y el desarrollo tecnológico, y de amenaza, por cuenta de la pandemia.

\section{Reflexiones finales}

En síntesis, por lo menos en términos de las experiencias espaciotemporales, hay varios indicios acerca de que esta crisis está provocando más reafirmaciones que transformaciones. Con algunas variaciones, ciertos rasgos que son propios de regímenes espaciales y temporales lentamente configurados durante los últimos dos siglos, se han visto fortalecidos por cuenta de esquemas geopolíticos y cronopolíticos exacerbados durante la pandemia. Ello resulta preocupante en varios aspectos: la hiperterritorialización del mundo, el fortalecimiento de autoritarismos y exclusiones basados en el control espacial, la homogeneización de los horizontes de futuro por cuenta de una imaginación histórica presentista, y la naturalización de un mapa del tiempo que reproduce hegemonías e inequidades en el ámbito global.

Por otra parte, la pandemia ha activado, de manera cruda, nuestra capacidad de comprender lo vulnerables que somos como especie. Algo que pese a todo resulta valioso, de cara a las crisis ecológicas que cada día preocupan más, las cuales han sido provocadas, a la vez que opacadas, desde una valoración antropocéntrica de nuestras relaciones con el mundo. Relativizar y situar en proporciones más justas la dimensión de la agencia humana, no impide reconocer que los regímenes espaciotemporales son modificables, y que los horizontes de futuro no están predeterminados. En este sentido, más que hacer predicciones más o menos optimistas o fatales, propongo observar algunos matices que pueden servir como referencia para trazar caminos menos penosos que los de una tragedia que ha ocupado el lugar del futuro, o los del retorno a una normalidad que, tal y como ha observado Sennett (2009), necesitaba ya demasiadas reparaciones.

Al respecto, ver los mapas de flujos planetarios de información, finanzas, mercancías, servicios y, sobre todo, de personas elaborados por McKinsey \& Company (2016). 
En primer lugar, y sin que se confunda con los nacionalismos de última generación, se ha demostrado que, por lo menos algunos gobiernos han sido capaces de entrar rápidamente a regular las dinámicas de la economía en pro de la salud de la población (Latour, 2020). Con ello, la imagen de un Estado de bienestar y solida$\mathrm{rio}^{4}$, ha recobrado importancia, en contravía de diversos discursos que desde hace años venían celebrando su debilitamiento o reclamaban su exclusiva funcionalidad para propiciar el mercado global. Y aun cuando hoy mismo las mercancías parecen tener una vida más libre que la de los humanos, en el sentido en que siguen transitando por fronteras que a nosotros nos están prohibidas, en algunas partes las necesidades de abastecimiento durante la pandemia han reactivado algunas prácticas locales y más próximas de producción y consumo. $\mathrm{O}$ en todo caso, la escasez de productos que son vitales para atender la pandemia (mascaras y respiradores artificiales) ha llevado a que se haga visible la inconveniencia de mantener un alto grado de dependencia frente a fuentes de abastecimiento lejanas. Ello lleva necesariamente a reconsiderar la manera en que vienen funcionado los Estados y las economías domésticas desde una geografía económica renovada. Se abren posibilidades de promover esquemas de comercio más próximo y justo, menos dependientes de las extensas redes globales, con sus múltiples nodos de especulación, y sus decisiones tomadas por fuera de los espacios en los que viven quienes producen y consumen.

Otro aprendizaje puede derivarse de las prácticas de teletrabajo, educación virtual y flexibilización de los horarios, que se han visto fortalecidas por cuenta de las medidas de confinamiento. Al ponerse en marcha, se han hecho evidentes los altos costos económicos y ecológicos que implica el que, todos los días, y a las mismas horas, miles de personas estuvieran saliendo a trabajar en espacios diferentes a los de sus viviendas. Aunque estas prácticas suponen transformaciones profundas en la organización de los ritmos y espacios de la vida cotidiana, y por lo tanto de las relaciones sociales, lo cual debe ser cuidadosamente estudiado en sus consecuencias, abren la posibilidad para explorar una mayor autonomía y diversidad en el manejo del tiempo, a la vez que contribuye a solucionar los problemas de movilidad, cuyos circuitos están desde hace ya décadas saturados en los espacios urbanos.

Más ampliamente, estos matices que se advierten en las prácticas sociales de la pandemia, llevan a replantear los términos en que se han venido establecido las articulaciones entre espacio, tiempo, economía y política. En primer lugar, está el imperativo de rápida producción, intercambio y consumo de mercancías, que Harvey (1989) ha identificado con una compresión espaciotemporal propia de la economía capitalista de las últimas décadas. Las concepciones sobre el crecimiento económico, y las formas en que esto se traduce en índices que aceleran aún más los ritmos ya frenéticos de producción y consumo, no deberían volver a hacer parte de la normalidad. Sería conveniente caminar hacia una descompresión espaciotemporal, mediante la redefinición de la regulación del mercado, de los hábitos de consumo, así como de los tiempos y espacios del trabajo, el estudio y el ocio.

4 Vale la pena precisar que me refiero al bienestar y la solidaridad para los ciudadanos, y no para las corporaciones financieras. Como en otras crisis, los organismos financieros privados esperan que sus "pérdidas" sean cubiertas con presupuestos públicos, mientras que no pocas empresas y bancos vienen incluyendo en sus estrategias publicitarias, mensajes de solidaridad que finalmente son estrategias para la maximización de ganancias. 
En segundo lugar, las dudas que han surgido, inclusive en gobiernos que se precian de neoliberales, en torno a los beneficios de una globalización orientada fundamentalmente por la economía capitalista, sumadas a las grietas que en algunas partes se observan en las rígidas estructuras que jerarquizan escalarmente la fuerza de las decisiones políticas estatales, llaman la atención acerca de la importancia de generar condiciones para poner en marcha políticas basadas en sentidos de lugar y región (Agnew, 1987; Dirlik, 1999; Escobar, 2000). Se trata de producir nuevos sentidos de lugar y región que, mediando una reflexividad crítica acerca de lo que constituye la singularidad de su conformación geohistórica y ecológica, generen condiciones para poner en marcha proyectos políticos que, además de atender a sus particularidades, regulen con sentido de pertenencia las relaciones, sobre todo económicas, entre lo global y lo local. No sobra indicar que el sentido de estas apuestas no descansa en esencialismos históricos y culturales, ni en la demarcación de espacios cerrados. Por el contrario, con fronteras porosas y abiertas a la pluralidad, estos proyectos, articulados heterárquicamente mediante redes interlocales e interregionales, son necesarios para contrarrestar aquellas dinámicas estatales y globales que perpetúan las jerarquías escalares de la modernidad. Igualmente, estas redes son fundamentales para dar tratamiento a problemáticas que, como la pandemia, y las crisis ambientales, son de carácter planetario. Para emplear las categorías propuestas por Koselleck (1993), los proyectos basados en el lugar y la región ofrecen la posibilidad de tejer relaciones novedosas entre los espacios de experiencia y los horizontes de expectativa, diferentes de aquellas, generalmente desarticuladas o desbalanceadas, que han operado en la cronopolítica y la geopolítica de la modernidad, así como en sus ulteriores transformaciones hacia una compresión espaciotemporal.

Vistas en perspectiva, las crisis y las pandemias no son extrañas a la historia, pero por sus graves efectos marcan momentos extraordinarios, y pueden generar transformaciones inesperadas o moduladas. En relación con la crisis actual, podríamos no hacer nada, y esperar a que todo pase, mientras la inmunidad colectiva o la selección natural hacen su trabajo. Pero resulta que los virus no actúan de manera democrática. Los más débiles no lo son precisamente por un azar genético, sino por el lugar que ocupan en estructuras políticas y económicas inequitativas. Generar conocimiento sobre esta y otras crisis, puede contribuir a que modifiquemos las características de su ocurrencia, así como a la reorientación de sus efectos.

\section{Referencias}

Agnew, J. (1987). Place and Politics: The Geographical Mediation of State and Society. Boston, MA: Allen and Unwin.

Agnew, J. (2003). Geopolitics: Re-visioning World Politics. New York, NY: Routledge.

Brenner, N. (1998). Between Fixity and Motion: Accumulation, Territorial Organization and the Historical Geography of Spatial Scales. Environment and Planning D: Society and Space, 16(4), 459-481.

Brenner, N. (2001). The limits to scale? Methodological reflections on scalar structuration. Progress in Human Geography, 25(4), 591-614. 
Emcke, C. (2020). La pandemia es una tentación autoritaria que invita a la represión. Entrevista de Juan Cruz, a Carolin Emcke. El País, 20 de abril. Recuperado de https:/elpais.com/cultura/2020-04-19/carolin-emcke-esta-es-una-tentacion-autoritariaque-invita-a-la-represion.html

Dirlik, A. (1999). Place-Based Imagination: Globalism and the Politics of Place. Review (Fernand Braudel Center), 22(2), 151-187.

Escobar, A. (2000). El lugar de la naturaleza y la naturaleza del lugar: ¿globalización o postdesarrollo?. En E. Lander (Comp.), La colonialidad del saber: eurocentrismo y ciencias sociales. Perspectivas latinoamericanas (pp.113-143). Buenos Aires, Argentina: CLACSO.

Fabian, J. (1983). Time and the Other: How Anthropology Makes Its Object. New York, NY: Columbia University Press.

Hartog, F. (2007). Regímenes de historicidad, presentismo y experiencias del tiempo. México: Universidad Iberoamericana.

Harvey, D. (1989). The condition of postmodernity: An enquiry into the origins of cultural change. Oxford, UK: Blackwell.

Johns Hopkins University. (2020). COVID-19 Dashboard by the Center for Systems Science and Engineering (CSSE) at Johns Hopkins University (JHU). Baltimore, USA: Johns Hopkins Coronavirus Resource Center. Recuperado de https://coronavirus.jhu.edu/

Koselleck, R. (1993). Futuro pasado. Para una semántica de los tiempos históricos. Barcelona, España: Paidós.

Latour, B. (2020). ¿Qué medidas de protección para evitar el regreso del modelo de producción de la precrisis? Bruno Latour webpage, 28 de marzo. Recuperado de http://www.bruno-latour.fr/fr/node/851.html

May, J., y Thrift, N. (2001). Introduction. En J. May y N. Thrift (Ed.), Timespace. Geographies of temporality (pp.1-46). New York, NY: Routledge.

McKinsey \& Company. (2016). Digital Globalization: the new era of global flows (Executive Summary, March 2016). New York, NY: McKinsey Global Institute.

Sennett, R. (2009). El artesano. Barcelona, España: Anagrama. 